\title{
AANS/CNS Section on Tumors
}

\section{0th Anniversary special issue}

\author{
Anthony D'Ambrosio • Fred G. Barker II
}

Published online: 3 September 2014

(c) Springer Science+Business Media New York 2014

This year marks the 30th anniversary of the founding of the Section on Tumors of the American Association of Neurological Surgeons (AANS) and Congress of Neurological Surgeons (CNS). In 1984, Dr. Edward R. Laws Jr. suggested forming this organization and Dr. Mark Rosenblum, one of our distinguished contributing authors to this publication, was the Section's first Chair. Since its inception 30 years ago, the AANS/CNS Section on Tumors has been committed to providing a forum through which neurosurgeons and allied specialists who focus on brain tumor research, diagnosis and treatment can communicate, educate and inspire each other toward the common goal of improving outcomes for our patients and their loved ones.

As research and technology continue to advance at an exponential rate, so does our understanding of the mechanisms behind, and the treatment opportunities for, tumors of nervous system. The first nine special contributions to this 30th Anniversary Supplement are designed to summarize the multiple advances in brain tumor research, diagnosis and management that have evolved over the past decade. Drs D'Amico, Kennedy and Bruce lead off with a summary of recent technical advances in brain tumor surgery. Dr. Rosenblum, the section's first Chair, has made

A. D’Ambrosio ( $\square)$

Neurosurgeons of New Jersey, 1200 East Ridgewood Avenue,

Ridgewood, NJ 07450, USA

e-mail: dambrosio@neurosurgerynj.com

F. G. Barker II

Neurosurgical Service, Massachusetts General Hospital, Boston,

MA, USA

e-mail: barker@helix.mgh.harvard.edu

F. G. Barker II

Department of Surgery (Neurosurgery), Harvard Medical

School, Boston, MA, USA two contributions discussing the world of neuro-oncology as seen through the patient's eyes. Advances in genetic and epigenetic analyses of gliomas are discussed in great detail by Drs. Tsankova and Canoll. The evolving role of imaging in neuro-oncology is thoroughly reviewed by Dr. Sarah Jost Fouke's group. Recent achievements and failures in medical neuro-oncology, including the most recent findings on bevacizumab are eloquently discussed by Drs. Ahluwala and Chang. Advances in fractionated radiation and stereotactic radiosurgery for both malignant and benign nervous system tumors are summarized by Dr. Jason Sheehan's group. Current Tumor Section Secretary-Treasurer Dr. Andrew Parsa addresses recent discoveries and ongoing challenges in the field of vaccine therapies for patients with glioblastoma. Finally, Dr. Isabelle Germano provides an extensive review and discussion on our past, present, and future understanding of stem cells and gliomas.

As our neuro-oncology knowledge base has expanded over the last 10 years, so has the Section on Tumors as an organization. The latter half of this special issue includes five articles describing the section's academic and organizational accomplishments as well as the challenges to be faced in the future. In an ongoing effort to educate physicians through evidence based medicine methodology, Dr. Mitchell and coauthors provide a current update on clinical practice guidelines in the Tumor Section. Dr. Ian Parney provides an update on the importance of ongoing clinical trials in neuro-oncology with an emphasis on the vital role neurosurgeons must play in this process. Drs. Waziri and Curry provide a description of the evolution, current status, and future challenges in the ongoing development of the Section. Awards, lectures and fellowships are eloquently described by Dr. Manish Aghi and coauthors. The supplement concludes with a look back at the History of the 
AANS/CNS Tumor Section Biennial Symposia as authored by Drs. Lang and Barker.

\section{Sincerely,}

Anthony D'Ambrosio and Fred G. Barker II

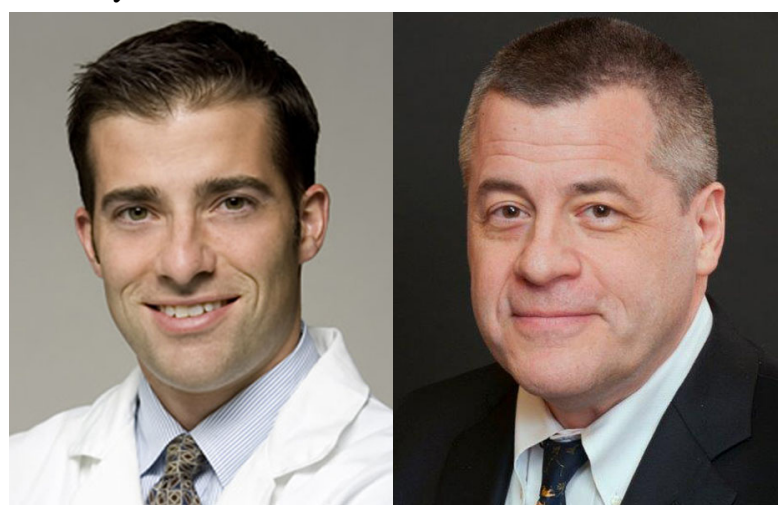

Acknowledgments We are exceptionally grateful to Dr. Linda M. Liau, Editor-in-Chief of the Journal of Neuro-Oncology, for her willingness, dedication and patience with this project. A special thank you is in order to all of the staff of the Journal for their hard work, responsiveness, and unsurpassed quality. We would like to thank all of the contributing authors for their time, effort and resources to make this special issue possible, and the many reviewers who volunteered their time and expertise to ensure a publication of the highest quality. 